\title{
SHOULDER COMPLICATIONS AS A CAUSE OF DELAY IN REHABILITATION OF SPINAL CORD INJURED PATIENTS
}

\author{
(Case reports and review of the literature)
}

\author{
By A. Ohry, M.D., M. E. Brooks, M.D., T. V. SteinbaCh, M.D. \\ and R. Rozin, M.D. \\ Sir Ludwig Guttmann, Spinal Cord Injury Center, Chaim Sheba Medical Center, \\ Tel-Hashomer and the Sackler School of Medicine, Tel-Aviv University, Israel
}

\begin{abstract}
We describe ten patients with spinal cord disease or injury who developed upper extremity and shoulder complications during rehabilitation. These shoulder complications caused delay in rehabilitation. We discuss the aetiology, treatment and management of shoulder complications in spinal patients and in patients with other neurological diseases.
\end{abstract}

Key words: Shoulder; Spinal cord injury; Spinal cord disease; Delay in rehabilitation.

\section{Introduction}

SPINAL cord injury or disease is a devastating illness which can limit people's independence in everyday activities. Any loss of upper extremity function for any reason is a serious blow of the already paralysed patients, for arms and hands become the limbs of locomotion either by crutch walking or wheelchair propulsion. During the course of the past few years we have seen several examples of patients with excellent potential, whose progress was severely retarded because of upper extremity complications. We present ten representative cases and then discuss aetiology treatment and management of these problems.

\section{Case Reports}

I. W.E., a 33-year-old man, fell from a height of $2 \frac{1}{2}$ metres. He suffered a compressed fracture of $\mathrm{D}_{5}$ vertebra with complete $\mathrm{D}_{5}$ paraplegia. He was treated with bed rest for Io weeks and then mobilised. When he began to walk with crutches and long leg braces, he suddenly began to complain of shoulder pain. X-ray film showed fracture of right clavicle which most probably was a result of his fall. We interrupted his physical activities until this fractured bone healed. But even afterwards he had much difficulty in propelling his wheelchair and in walking.

2. T.G., a 22-year-old soldier, suffered a gunshot wound causing incomplete $\mathrm{D}_{7}$ paraplegia. His recovery and rehabilitation were satisfactory. However, pain in the right index (distal phalanx) and habitual dislocation of left shoulder prevented him from reaching his full potential. X-ray film showed thickening of bone material in that phalanx and an ostoid osteoma was surgically removed. When he became active in a wheelchair or when he began to walk (with two crutches only) repeated shoulder dislocations occurred, and were replaced manually. No surgical correction was performed for this.

3. M.A., a 47-year-old man, sustained a fracture of L2 vertebra as a result of an incomplete cauda equina in I960. His sensation is normal, but his motor deficit includes 
neither glutei nor dorsi nor plantar flexors of the ankle. He has an upper motor neuron bladder, erection and ejaculation. $\mathrm{He}$ is very active in sport for the handicappedmostly in athletics. He came to our outpatient clinic complaining of severe shoulder pain and especially in externally rotating and abducting his arm. Clinically and regenographically, he seemed to have a rotator cuff tear, probably resulting from hand sports activities. Rest and avoidance of physical activities led to a complete recovery.

4. N.B., a 45-year-old man, was admitted with incomplete C6, 7 tetraplegia. He complained of increasing left shoulder pain. Examination revealed that he had developed 'frozen shoulder' limiting his independence in a wheelchair. Corticosteroids and Novocaine intra-articular injections with physical therapy slowly improved the full range of his shoulder motion.

5. E.K., a 25-year-old man, was admitted after falling into a large candy mixer in a factory, resulting in a head injury, complete $\mathrm{C}_{5}, 6$ tetraplegia fractures of right clavicle, ribs and all extremities. All his fractures were fixated either internally or externally, but because of his fractured clavicle, his shoulder activities were significantly reduced.

6. Y.S., a 32-year-old soldier, injured in a war accident resulting in quadriparesis (central cord syndrome). He gained complete independence in daily living activities, but developed a right frozen shoulder, on his weaker side. This resulted in nearly complete disuse of this hand. His clinical picture was of 'shoulder hand syndrome'.

7. Another similar clinical course had occrured to K.G., a 23-year-old soldier, who was injured by a gun shot, resulting in complete $\mathrm{C}_{5}$ tetraplegia. The development of shoulder-hand syndrome had occurred during the long period in bed. Physical therapy had succeeded in improving the function of his shoulder.

8. K.F., a 54-year-old woman, was admitted to our department after removal of a Di2 meningioma, causing complete DII spastic paraplegia. Shortly after becoming independent in A.D.L., she complained of shoulder pains. Physical therapy and local cooling was of some benefit, but after a prolonged period of pushing the wheelchair, she developed bicipital tendinitis and local steroid injection helped her. Because of the severe pain she had difficulty in wheeling her chair.

9. A.C., a 22-year-old soldier, suffered a gunshot wound resulting in complete $\mathrm{C}_{4}-5$ tetraplegia. One year after the injury, he developed a frozen shoulder responding to corticosteroid therapy.

10. The last case is not similar to the others-a 22-year-old soldier, who came down with severe bulbar poliomyelitis. Three months after admission to the rehabilitation department he developed contracture of both pectoral muscles, causing pain in every attempt to turn him or to change his position. Progressive physiotherapy and analgesic therapy helped this condition.

\section{Discussion}

There is a close connection between neurological problems and shoulder mechanics. Painful restriction of shoulder movements was recognised in the last century as a sequel to anginal attacks. Osler (1897) was the first to describe this association. Later, other 'reflex neurovascular' disorders of the shoulder, arm and hand were called 'shoulder-hand syndrome'. This can also be seen in the following situations: myocardial infraction, cerebral vascular accident and trauma, as mentioned in the Lancet (Editorial, 1974). The features of this syndrome were indistinguishable from capsulitis, that is pain, stiffness, tenderness and limited movements of the shoulder, thus resulting in a flexion deformity of fingers, 
contractures, atrophy of muscles and trophic skin changes. Early mobilisation and active physiotherapy may fail to prevent occurrence of the condition, so small doses of corticosteroids may be effective even though Flatt (1974) opposes this, and points out the importance of the venous pumping mechanism in the hand and axilla in the pathenogenesis of these conditions. The phenomenon of periarticular new bone formation in the shoulder and other joints is well known, although the aetiology is not. Dejerine et al. (I9I8) and Stover et al. (1975) noted in patients with spinal cord injuries severe head injuries, Mendelson et al. (1975) and Mielants et al. (1975) after long-term coma, but not in patients with cerebrovascular accident having subluxation of the gleno-humeral joint. In both conditions, the shoulder disability resulting from the primary neurological lesion seriously affects the patients during the rehabilitation process. The problem of primary 'frozen shoulder' was discussed thoroughly by Weiser (1976). This syndrome is characterised by restriction of movements in the gleno-humeral joint, abduction to $55^{\circ}$, external rotation from $0^{\circ}$ to $50^{\circ}$, no clinical history of trauma, fractures, rheumatologic or neurological diseases.

Codman (1934) summarised the situation: 'there is a class of cases which I find difficult to define, difficult to treat and difficult to explain from the point of view of pathology'.

Another situation affecting shoulders is neuralgic amytrophy or ParsonageTurner syndrome (Cohn et al., 1975). This syndrome consists of severe pain of sudden onset in the shoulder girdle and arm, with weakness and wasting of the affected muscles. The pain may last a few weeks and the weakness and wasting of muscles are not necessarliy reversible. The onset of the disease in all their patients occurred during the cold season. The differential diagnosis includes acute anterior poliomyelitis, cervical disc herniation, and other space-occupying lesions, neuritis of various origins and neuromuscular diseases such as amyotrophic lateral sclerosis.

Degenerative and traumatic disorders involving the extra articular structures about the shoulder joint are quite common among individuals past 40 years of age. The painful shoulder is probably the most frequently disturbing complication in the stroke patient, and it interferes with active function and the performance of daily activities. Several factors may be involved in the painful shoulder of the hemiplegic patient.

I. Pre-existing degenerative changes in the rotator cuff.

2. Repeated small trauma to the periarticular structures, incurred as a result of traction on the shoulder while the unconscious patient lies on the hemiplegic arm, or when he tries to move in bed with the arm flaccid at his side.

3. Excessive traction of the shoulder capsule, with marked inferior displacement of the humeral head in a flaccid limb.

4. Vigorous stretching of the 'tight' spastic shoulder during physical therapy, producing further trauma to the cuff and long head of the biceps-tendon.

5. Unrecognised trauma such as an impacted fracture of the surgical neck of the humerus, incurred as a result of falling-during the onset of the stroke.

6. Contractures that occur in the untreated patient or develop as a result of peripheral nerve lesion and heterotopic calcification or ossification.

The treatment consists of using a sling (although it may agravate the abduction-internal rotation contracture in a painful spastic shoulder), local infiltration of the long head of the biceps tendon with procaine and corticosteroids and physical therapy. Many hemiplegic patients develop pain in the upper 
extremity as a result of reflex sympathetic dystrophy. This is a syndrome consisting of pitting oedema, cyanosis, limitation of extension in the wrist and finger joints. It should not be confused with the shoulder-hand syndrome (reflex dystrophy), which occurs in about 5 per cent of stroke patients (Rusk, I97I).

According to the Lancet (Editorial, 1976), this syndrome is characterised by pain, swelling of the hand, trophic skin changes, vasomotor instability and precipitating factors such as myocardial infarction, trauma, spinal-disc disease or stroke. The continuation of steroid therapy is discussed and it is emphasised that prolonged immobilisation undoubtedly leads to juxta-articulator and soft tissue swelling, muscle atrophy contractures, osteoporosis ('Sudek's Atrophy') and bony erosions.

Rosin (1975) showed that hemiplegic patients' shoulders may also be affected by para-articular ossification-causing another complication to the affected arm.

Although rotator cuff tear is rare in dorsal spinal cord injured patients, we had checked only one case with such a condition after vigorous sport activities. This condition is of relative frequency in stroke patients. Wolfgang (1974) showed that the diagnosis of the rotator cuff was confirmed by direct (surgical) intervention and previous arthrography. In the majority of cases the results of surgical repair were excellent. The results were better if pre-operation X-ray films were normal or if the tear was partial, while results tended to be worse if these neocalcifications were deposited in the cuff. The characteristics of patients with rotator cuff are: over 40 years of age, history of trauma, labouring occupation, painful shoulder motion, night pain, weak or absent abduction, tenderness, palpable crepitus during passive motion, a gap palpable in the region of the cuff, some functional deficit, atrophy of supra and infraspinatus muscle bellies, irregularity of motion with respect to the coordination of scapular and humeral movement and decreased motion of the whole shoulder.

Another condition was reported by Groves and Goldner (1974). Three adults had abduction contractures of the shoulder due to fibrosis of the deltoid muscles and they related this condition to frequent intramuscular injections to the deltoid muscle-causing pressure ischaemia there. The problem of shoulder muscle contracture (as in patient No. Io-described above) is serious and very difficult to help.

The problem of rotator cuff tear versus suprascapular nerve injury is discussed thoroughly by Donovan and Kraft (1974). Five cases involving the differential diagnosis of inadequate shoulder abduction were presented and the importance of EMG and arthrography in distinguishing rotator cuff and suprascapular nerve lesion was discussed. Both types of injury may be presented as a problem of abduction of the shoulder in the presence of strong deltoid contraction, and both may show considerable atrophy of supra and infra spinatus. The importance of the integrity of the rotator cuff in carrying out normal abduction has been recognised for some time. Some authors postulated the existence of mechanical force couple at the gleno-humeral joint consisting of the deltoid and cuff muscles. The deltoid alone draws the humeral head into the glenoid and the cuff muscles, while contracting alone-should produce subluxation of the humerus inferiorly.

One patient in our series suffered from chronic dislocation of the shoulder, disturbing his walking and daily activities. Rosenorn and Brix-Pederson (1974) discuss the treatment of dislocation of the acromio-clavicular joint and, Morreg and James (1976), the problem of recurrent anterior dislocation of the shoulder. The acromioclavicular ligament serves as a reinforcement for the joint capsule, its fibres connecting the upper edge of the acromion, some fibres being interwoven 
with the capsule. The results of the previous study of Rosenorn of post-mortem investigation of the acromioclavicular joint were presented. They concern experiments involving division of the structures around the joints, the mobility of which has been examined clinically and radiologically and have shown acromioclavicular dislocation may occur without injury of the coracoclavicular ligament.

A proper evaluation of the success of any surgical procedure for recurrent dislocation of the shoulder must be based on a long-term follow up. Surgical failure is more frequent if the patient has bilateral dislocation, posterior dislocation or a history of shoulder dislocation.

Some of our patients suffered from clavical fracture which bothered them very much in their activities. Comarr et al. (1962) presented a study of their experience with fractures of extremities of spinal cord injured patients. One group of patients with fractures of upper extremity incurred at the injury, the second group with fractures of lower extremities incurred also at the time of injury, and two other groups with late fractures of upper and lower extremities. The authors described all the distribution of the fractures and the effect on rehabilitation. They were all treated conservatively with with good results. Much literature concerned shoulder complication in hemiplegic patients-as mentioned previously.

The shoulder hemisling is commonly used to support the shoulder and arm of the hemiplegic patient with a flaccid upper extremity. Hurd et al. (1974) found no appreciable difference between the treatment or control group, using the parameters of shoulder range of motion, pain or subluxation and there was no evidence of increased incidence of peripheral nerve or plexus injury. They concluded that the hemisling as traditionally designed need not be uniformly applied to all such patients following C.V.A.

The paralysed shoulder joints of an hemiplegic patient with pain-limitation of motion and/or subluxation were studied using contrast arthrography by Nepomuceno and Miller (1974). Eight patients showed structured soft-tissue lesions in the form of rotator cuff and transverse bicipital ligaments tear. Seven of the eight patients with abnormal arthrogram had left hemiplegia. The significance and possible benefit of surgical intervention and variation from standard therapy for hemiplegic patients were suggested. Arthrography helps evaluate pain or immobility of obscure origin, although no patient described above underwent such procedure. Weiss et al. (I976) showed that shoulder arthrography can confirm the diagnosis of frozen shoulder and reveal the presence of rotator cuff tears, active synovitis - or a combination of these conditions. The results of arthrography do influence therapy. Patients with abnormal arthrography are treated with antiinflammatory drugs, ultrasound or intra-articular injection of steroids. In patients with normal arthrograms, drug therapy has minimal effect.

The emphasis is on increasing range of motion with particular use of wall climbing and Codman's pendular exercise. Corticosteroid intra-articular injection proved itself in the treatment of frozen shoulder due to any cause, arising from supra-spinatus tendon, subdeltoid bursitis bicipital tendon or the capsule itself (Steinbrocker and Argyros, 1974).

In the review of the literature concerning shoulder problems, we must mention two important works. The first (Herberts and Kadefors, 1976) deals with painful shoulder in welders. The study revealed that the older workers with shoulder pain have a chronic tendinitis of rotator cuff (and perhaps the wheelchair pushers also?). The supraspinatus muscles were shown to be consistently fatigued during overhead welding and it was believed that this was an important factor in the aetiology of the shoulder pain commonly occurring in older welders 
and perhaps in other occupational diseases. The other paper (Vebostad, 1975) deals with calcific-tendinitis of the shoulder region, especially the supra-spinatus tendon. It is generally agreed that most patients respond well to conservative treatment with good prognosis. Surgical treatment is reserved for those whose prolonged conservative treatment has failed.

Review of the literature revealed a lack of studies on problems of the shoulder in spinal cord injured patients. We have attempted to discuss and correlate problems of a similar nature arising in other diseases and injuries. In the spinal cord injured patient especially, the high level paraplegic and the quadriplegic, a 'minor' shoulder injury can cause a marked delay in the mobilisation and rehabilitation of these patients. Conclusions discussed in studies of hemiplegic and traumatic shoulder injuries are applicable to spinal cord injured patients.

\section{SUMMARY}

Nine cases of spinal cord injured patients and one with poliomyelitis are presented. Each case presents an upper extremity complication which complicated their rehabilitation process. follows.

A discussion of aetiology, treatment and management of these problems

\section{RÉSUMÉ}

9 cas de patients atteints à l'épine dorsale, et un de poliomyélite, sont présentés. Chaque cas présente une complication des extrémités supérieures qui rendit plus difficile leur rééducation. Une discussion de l'étiologie et du traitment de ces problèmes suit.

\section{ZUSAMMENFASSUNG}

Es werden 9 Fälle rückenmarkverletzter Patienten und ein Kinderlähmungsfall vorgestellt. Bei jedem Fall liegt eine Komplikation der oberen Glieder vor, die Rehabilitierung erschwerte. Es folgt eine Diskussion der Etiologie und der Behandlung dieser Probleme.

\section{REFERENCES}

Codman, E. A. (1934). Shoulder: Rupture of Supraspinatus Tendon and other Lesions in or about Subacromian Bursa. T. Todd Co., Boston.

Cohn, D., Avrahami, E. \& Streifler, M. (1975). Neuralgic amyotrophy. Harefuah, 89, 8-II.

ComarR, A. E., Hutchison, R. H. \& Bors, E. (1962). Extremity fractures of patients with spinal cord injuries. Amer. F. Surg., 103, 732-739.

DeJERINE, MME \& CEILIER, A. (I9I8). Les paraosteo arthropathies des paraplegiques par tensions medullaries. Rev. Neurolog., 26, 348.

Donovan, W. H. \& KRAFT, G. H. (I 974). Rotator cuff tear versus suprascapular nerve injury: a problem in differential diagnosis. Arch. Phys. Med. Rehabil., 55, 424-428.

EDITORIAL (1974). Shoulder-hand syndrome, Lancet, I, 850.

EDITORIAL (I976). Reflex sympathetic dystrophy syndrome, Lancet, I, I226-I227.

FLATT, A. E. (I974). Shoulder-hand syndrome, Lancet, I, I IO7-I IO8.

GROVES, R. J. \& GoldneR, J. L. (1974). Contraction of the deltoid muscle in the adult after intramuscular injection-report of 3 cases. F. Bone foint Surg., 56A, 817-820.

HeRberts, P. \& KADEFors, R. (1976). A study of painful shoulder in welders. Acta Orthop. Scand., 47, 38I-387.

Hurd, M. M., FarRelL, K. H. \& WaYlonis, G. W. (1974). Shoulder sling for hemiplegia: Friend or foe? Arch. Phys. Rehabil., 55, 519-522.

Mendelson, L., Grosswasser, Z., Najenson, T., SAndbank, U. \& Solzi, P. (1975). Periarticular new bone formation in patients suffering from severe head injuries. Scand. F. Rehabil. Med., 7, I4I-I45. 
Mielants, H., Vanhove, E., De Neels, J. \& Verys, E. (1975). Clinical survey of and pathogenic approach to para-articular ossifications in long term coma, Acta Orthop. Scand., 46, I90-198.

MORREG, B. F. \& JAMES, J. M. (I976). Recurrent anterior dislocation of the shoulder. 7. Bone foint Surg., 58A, 252-256.

Nepomuceno, C. S. \& Miller, J. M. (I974). Shoulder arthrography in hemiplegic patients. Arch. Phys. Med. Rehabil., 55, 49-71.

OsLer, W. (1897). Lectures on Angina Pectores and allied states. New York.

RosenoRn, M. \& BRIX-PEDERSON, E. (I974). The significance of the coroco-clavicular ligament in experimental dislocation of the acromioclavicular joint. Acta Orthop. Scand., 45, 346-358.

Rosin, A. J. (I975). Ectopic calcifications around joints of paralysed limbs in hemiplegia, diffuse brain damage and other neurological diseases. Ann. Rheum. Dis., 34, 499-505.

Rusk, H. A. (I97I). Rehabilitation of patients with stroke. In Rehabilitation Medicine, 3rd Edition, p. 625. C. V. Mosby Co., St Louis.

SteINBROCKER, O.\& ARGYROS, T. G. (I974). Frozen shoulder: treatment by local injections of depot corticosteroids. Arch. Phys. Med.Rehabil., 55, 209-213.

Stover, S. L., Hataway, C. J. \& ZeIser, H. E. (I975). Heterotopic ossification in spinal cord injured patients. Arch. Phys. Med. Rehabil., 56, I94-204.

Vebostad, A. (1975). Calcific tendinitis in the shoulder region-a review of 43 operated shoulder. Acta. Orthop. Scand., 46, 205-2 ro.

WeISER, H. I. (1976). Mobilization under local anesthesia for painful primary frozen shoulder. Harefuah (J. Isr. Med. Assoc.), 90, 2 I 5-2 I9.

Weiss, J. J., Thompson, G. R., Doust, V. \& Burgener, F. A. (1976). Arthrography in the diagnosis of shoulder pain and immobility. Arch. Phys. Med. Rehabil., 55, 205-209.

WolFGANG, G. L. (I974). Surgical repair of tears of the rotator cuff of the shoulder-factors influencing the results. F. Bone foint Surg., 56A, 14-26. 